\title{
The Effect of Housing Quality on Self-Reported Health Status in
} Cameroon

\author{
Elizabeth Ankiambom Chiatii $^{{ }^{*}} \quad$ Njong Mom Aloysius $^{2}$ \\ 1.PhD Student, Department of Economics, University of Bamenda, Cameroon \\ Email:*siseliz@yahoo.com
}

1.Senior Lecturer and Head of Department for Economics, Faculty of Business and Management Sciences, Catholic University of Cameroon (CATUC) Bamenda. P.O. Box 782, Bamenda, Cameroon Email: *siseliz@yahoo.com

2.Njong Mom Aloysius (PhD), Professor, Development Economics, Dean of the Faculty of Economics and Management Sciences, The University of Bamenda, P.O. Box 39 Bambili,

North West Region, Cameroon

Email:mom_aloys@yahoo.fr

\begin{abstract}
Housing and health nexus has become a widely area of concern among many researchers. This study concentrates on housing quality and self-reported health status in Cameroon. The two concepts are inextricably intertwined. Housing quality is an essential social determinant of health but in Cameroon it tends to be a neglected site for public health action. Housing conditions play a major role in the health status of the individual and a wide variety of housing features have been reported to influence the physical, social, economic, healthy living and well-being of occupants. This study uses the 2014 Cameroon Household Consumption Survey (CHCS 4, 2014) from the National Institute of Statistics. This dataset is built from a survey study on 46,090 households. The method of data analysis employed is the ordered logistic regression given that self-reported health status is an ordered dependent variable. The respondents were asked to declare their state of health through a Linkert scale question-whether it is very good, good, bad and very bad. The 38 housing components contained in this data are computed in to an index with the use of the multiple correspondence analysis and a housing quality normalized score constituted as the dependent variable. The Analytical tool used for objective one is the simple Multiple Regression Analysis. The results indicate that most of the housing components have a significant negative impact on housing quality. This is an indication of poor housing of most low-income earners in Cameroon. Objective two Results of the ordered logistic regression technique indicate that an improvement in the housing quality of household members will create a likelihood of their health having a $1 \%$ significant change from a lower health category to a higher health category by $27 \%$. In other words, high standard housing condition guarantees protection against communicable diseases, protection against injury, poisoning, and chronic diseases, and reduce psychological and social stress to a minimum. This study recommends that the local governments should provide a variety of housing alternatives with regards to tenancy and payment, such as short-term rental, long-term lease, cohousing, and financed purchase. This will help remedy the problem of availability and affordability thus curbing the problem of housing inequality in Cameroon. Secondly, the government could ensure a free access to medical facilities. If the majority of the population have sponsored health expenses from the government, this will curb even the health inequalities among the poor and non-poor.
\end{abstract}

Keywords: Housing quality, Environmental housing components, Internal housing Components, Physical Housing indicators, Self-Reported Health Status

DOI: $10.7176 / \mathrm{JESD} / 12-10-02$

Publication date:May $31^{\text {st }} 2021$

\section{BACKGROUND OF STUDY}

1.1 Introduction

The high prevalence of health complaints across countries suggests that people feel unhealthy. A slight negligence of this important aspect of life may lead to very detrimental outcomes in the economy. (Greg et al., 2017). In any community of the world, it is confirmed that good health and medical care constitute central elements to human happiness and well-being, especially to public health. (Quddusi, 2020). Researchers like Maêns, R. \& Bengt (2001), reiterate that good health guarantees life expectancy, contributes significantly to prosperity and wealth and even economic progress, as healthy populations are more productive, save more and live longer. Self-rated health (also called Self-reported health, Self-assessed health, or perceived health) is commonly investigated in epidemiological surveys of health, and has been used as an indicator of a person's overall wellbeing in terms of social, biological and psychological health. It is often measured using a subjective question such as, 'In general, how would you rate your health?' with response categories ranging from 'poor' to 'excellent', or equivalent terms. (Subramanian, et al., 2020). some studies have found out that self-reported health status (SRHS) is greatly correlated with mortality. That is, those with poor health status have high chances of facing mortality risk. 
(Boscardin et al.,2015). Many factors account for the health status of individuals in the community. The Housing component constitutes one of the social determinants of health.

Housing is one of the traditional areas of concern for public health, though it has been relatively neglected over recent decades. However, housing is important for many aspects of healthy living and well-being. Housing conditions must be considered as one of the mechanisms through which social inequality translates into health inequality. The quality of housing where people spend over $80 \%$ of their time daily is crucial for healthy living and people's well-being. Improved housing conditions can save lives, prevent disease, increase quality of life, reduce poverty, help mitigate climate change and contribute to the achievement of the Sustainable Development Goals (SDGs), including those addressing health (SDG 3) and sustainable cities (SDG 11). Housing is becoming increasingly important to health due to demographic and climate changes. (WHO, 2018)

According to WHO (2018), Healthy housing is shelter that supports a state of complete physical, mental and social well-being. Healthy housing provides a feeling of home, including a sense of belonging, security and privacy. Healthy housing also refers to the physical structure of the dwelling, and the extent to which it enables physical health, including by being structurally sound, by providing shelter from the elements and from excess moisture, and by facilitating comfortable temperatures, adequate sanitation and illumination, sufficient space, safe fuel or connection to electricity, and protection from pollutants, injury hazards, mold and pests. Whether housing is healthy also depends on factors outside its walls. It depends on the local community, which enables social interactions that support health and well-being. Finally, healthy housing relies on the immediate housing environment, and the extent to which this provides access to services, green space, and active and public transport options, as well as protection from waste, pollution and the effects of disaster, whether natural or man-made (Bonnefoy, 2007)

The right to adequate housing facilities is a social right and of vital importance. Every human person has a right to proper accommodation. On a contrary, many low-income earners still suffer from homelessness, inadequate housing and overcrowding, especially in urban towns. (Golay \& Özden, 2007). The problems of haphazard urban construction and the question of squatter settlements presents a major challenge in most Cameroonian cities. (Fombe \& Balgah, 2010; Amawa \& Kimengsi, 2012; Achankeng, 2003; Ndenecho \& Lambi, 2002). The escalating growth in the numbers of people in nearly all regions of Cameroon is alarming. Consequently, this population growth crisis generates numerous problems like poor and inadequate housing conditions, anarchical construction- a possible source of future conflicts. Some determinants of housing challenges include inadequate shelter, difficulty in getting building permits, poor urban planning, non-respect of building codes, poverty, exorbitant rents, anarchical sprawling of settlements, demolition of houses and the state inability to ensure relocation facilities to victims. A major problem raised by the urban population is that the process of acquiring building permits remains very costly in terms of time and money. (Kimengsi, et al, 2015)

A range of studies indicate that most low-income earners in Cameroon have poor quality and inadequate housing. This contributes greatly to the health hazard such as malaria, cardiovascular disease, typhoid, etc. Poor internal housing conditions could cause poorer health conditions. This study necessitates a deeper look in to the housing conditions of the Cameroonian population and ensure appropriate strategies to improve the living conditions in order to curb the health hazards recurrent among the low-income earners.

\subsection{Statement of the Problem}

Housing quality constitutes a major social health challenge in Cameroon. The proliferation and rampant nature of informal settlements in Cameroon is a very big challenge, especially to the health of the general public. A range of factors explain why this is becoming rampant. Some of these factors include a deficit of housing supply, unaffordable housing rental rates, critical market factors, weak legal and institutional systems, and the socioeconomic conditions of the country. (Engoh \& Kakdeu, 2021). Most citizens of Cameroon have poor housing conditions, especially the low-income earners. The dilapidating poor housing quality embodies a variety of areas, namely homelessness, overcrowding, insecurity, housing that is in poor physical condition, and people living in deprived neighbourhoods. Some determinant factors of inadequate housing include poverty, low-income levels and unemployment, lack of access to land, housing supply constraints, urbanization, insecure property rights for land and housing, poor government policies and regulatory frameworks. (Fombe, 2012; Fombe \& Balgah, 2010; Kimengsi et al.,2015; Ojong, 2011; Socpa, 2010)

According to the Ministry of Housing and Urban Development, Cameroon (2012), the supply and demand for housing has always been in disequilibrium. The housing policy of Cameroon has been unable to curb this gap in spite of all its efforts. In this context, the problem of informal housing in Yaoundé, Douala and other major towns have gained roots. According to the World Population Prospect, Cameroon's population growth rate is at an alarming 2.6\%. Its 2020 projections from the same source stood at 26.55 million, up from its 2002 survey which was 17.4 million. The CIA World Fact Book records that the urbanization rate in Cameroon currently stands at $3.63 \%$ with 52.6\% having been urbanized to date. World Bank (2018), indicates that Cameroon has experienced a rapid rate of urbanization increasing from $13 \%$ in 1960 to 54\% today, making the country to have one of the highest 
rates of urbanization in Sub-Saharan Africa with $56 \%$ of the population now living in urban areas. In terms of forecast, the UN states that by $2050,70 \%$ of Cameroon's population will live in urban areas (Ibid). Given the phenomenal increase in the populations of the cities of Douala and Yaoundé, the availability of housing at affordable rates is on a decline. This affects mostly the low-income earners who find themselves in deplorable housing conditions

According to (UN-Habitat, 2015b; Brown, 2015), informal housing can be defined as residential areas where occupants often have no guarantee for the land or houses, they live in; for example, they may squat or rent informally. Such areas frequently lack basic services and city infrastructure. Settlement in such areas may not abide by planning and building procedures and is regularly located in geographically and environmentally hazardous areas. According to the National Institute of Statistics, 47\% of the population of Douala and Yaoundé live in informal settlements (Cameroon Household Consumption Survey CHCS 4, 2014). According to World Bank (2002), These two cities are followed by the secondary towns of Garoua, Bamenda, and Maroua, which have more than 200,000 persons each. The majority of peri-urban residents live in poorly drained and poorly serviced areas. The water supply and sewage sector are particularly affected by the deterioration of public services. Consequently, health indicators have deteriorated.

The increase in population especially in most urban towns like Yaounde and Douala cause overcrowding, catastrophic living conditions for most low-income Cameroonians, and thus health inequalities. (Boniface et al., 2003). The exaggerated population increment is as a result of the high Rural-urban migration of locals and foreigners, usually, from the West African region flocking to the major cities like Douala and Yaoundé in search of better economic opportunities. Unfortunately, this mass movement puts immense pressure on the housing sector. The consequences of this prevailing unfortunate situation are the prevalence of low-quality houses, further escalated by the high cost of building materials. There are very few exceptions, which are the high-class residential areas that are exceedingly expensive and thus meant only for the high-income earners who can afford the high rents. (Diamond Reality Real Estate Company Cameroon, 2019).

This housing issue has always been a preoccupation for the government of Cameroon. In an attempt to find a solution to this poor housing conditions, the government initiated the Olembe Low-Cost Housing Scheme. This project started in the year 2012 with the construction of 660 housing units in Mbanga-Bakoko, Douala and another 660 apartments in Olembe, Yaoundé. The project was officially completed by April 2017. At this juncture, a total of 1675 apartment were open for sale in response to the need of over 2,000 applicants for housing. More than 800 housing units were sold, costing between FCFA 19,587,750 to FCFA 22, 314,250 per unit. (Diamond Reality Real Estate Company Cameroon, 2019). This effort of the government is still insufficient to resolve the housing challenges in most of the regions of Cameroon. One of the factors is the is the inferior quality of materials used in constructing these houses. This puts a lot of doubts with regards to the living conditions, availability of pipe borne water, electricity and security. (Diamond Reality Real Estate Company Cameroon, 2019).

In most major town of the regions in Cameroon, the provision of urban housings is the fruit of some relatively small-scale, private building projects by private individuals or companies. Government plays a vital role by encouraging construction of houses and provision of a legal framework. Most new housing in the major towns like Buea and Bamenda, are being constructed for prosperous individuals or families (some of whom are living transnational lives) who are either seeking a home for themselves or are seeking an income from rents by becoming landlords. (Fombe, 2012; Fombe \& Balgah, 2010; Kimengsiet al.,2015; Ojong, 2011; Socpa,2010. The conundrum of inadequate housing is consequential to health. According to the WHO (2018), there are Key health risks related to housing. This unfortunate situation provokes numerous questions and worries in most Cameroonians, especially those involved in the scientific research field.

\subsection{Research Questions}

1. What are the determinants of housing quality in Cameroon?

2. To what extent does housing quality influence self-reported health in Cameroon?

3. What could be the policy implications for housing quality and self- reported health status in Cameroon?

\subsection{Research Objectives}

1. To identify the housing quality determinants in Cameroon

2. To assess the direct effect of housing quality on self-reported health status in Cameroon

3. To identify policy implications for housing quality and self- reported health status in Cameroon

\subsection{Research Hypotheses}

On the basis of the forgoing research questions and objectives, this thesis assesses the following alternative hypotheses:

1. Housing quality has some determining factors within the context of Cameroon

2. Housing quality is likely to have an effect on self-reported health status in Cameroon. 


\section{LITERATURE REVIEW}

Research into the relationship between housing and health has frequently been narrowly focused, fragmented, and of marginal practical relevance to either housing or health studies. Population health research, in its reference to the importance of the social and physical environment, rarely mentions housing. While it has been recognized for some time that there is a need for the development of a coordinated, integrated and cumulative body of housing and health research, there is still very little formal co-ordination between housing policy and population health policy. More attention needs to be paid to measuring the nature and extent to which better housing might improve population health. This is not an easy task. Because of the lack of a general theory of the mechanisms by which housing affects population health, serious methodological difficulties are associated with multidisciplinary research on the topic. (Hwang, et al, 1999). In some recent years, some writers have attempted a research in this area of study.

Baker et al (2016), worked on the area of poor housing quality: prevalence and health effects. According to them, housing is on the principal social determinants of health and well-being. Unfortunately, this area of study in Australia is scantily developed. This is mainly because from the majority of the population are accommodated in good quality housing. The dominance of a "good housing paradigm" means that households living in poor quality and unhealthy housing are doubly disadvantaged - by the quality of their housing and because policy makers in Australia do not acknowledge the health effects of housing. This work bases its analysis on data from the Household Income and Labour Dynamics in Australia (HILDA) survey, a panel dataset that is representative across Australia. It finds a sizeable, policy-important, and to date under-acknowledged cohort of Australians whose health is influenced by poor-condition dwellings.

The United States Department of Housing and Urban Development (HUD) 2007, worked on Housing quality and health outcomes in the United States. The American Housing Survey determined that 6 million households live with moderate or severe physical housing problems. Homes that are lacking toilets, have faulty or unreliable heating systems, or have exposed electrical wiring do not protect inhabitants from disease and injury and can cause serious psychological stress are categorized as being "severe" housing problems. "Moderate" housing problems are things such as having unvented gas, oil, or kerosene as the primary heating source, or lacking a kitchen sink. Again, the lack of commonplace appliances like a furnace or sink can expose inhabitants to diseases and injury. The U.S. Census Bureau gathers data on several factors related to the housing: plumbing, heating, hallways, upkeep, electric service and kitchen equipment. As many as 24 million households have led-based paint hazards. Maintenance and upkeep of public and low-income housing remains a major issue, leading to chronic problems of water infiltration, pest infestation and unsafe physical conditions. The disproportionate burden of these problems falls to children, the elderly and those with chronic illnesses, and minorities.

Adekunle et al (2018), researched on housing quality and risk factors associated with respiratory health conditions in Nigeria. This chapter presents an overview of the condition and quality of housing in Nigeria and its implication on respiratory health. Addressing housing issues offers public health practitioners an opportunity to assess an important social determinant of health. This chapter detailed the housing characteristics in Nigeria and revealed that respiratory health conditions, especially among children is associated with certain environmental factors that perturb the composition of the indoor air, and thus the housing quality. Drawing on this perspective, this chapter pursues the following questions: (1) What are the factors that affect the quality of housing where people spend most of their time daily? and (2) Given the housing condition in Nigeria, what housing-related factors influence the prevalence of respiratory health conditions especially among children? In the course of the discussion, we described the meteorological conditions of houses in relation to respiratory conditions, established a link between indoor air and housing quality, and elucidated the indicators for evaluating housing quality. Drawing on the associated risk factors, it argues that the quality of housing, including the external and internal structures, as well as the internal environment has a selective force on the respiratory health status of its occupants.

Greg et al (2017), assessed the relationship between self-reported health status (SRHS) and signs of psychological distress within European urban contexts. The study sample population constituted 20,439 adult respondents to surveys conducted across thirty-seven urban states. The method to analyze SRHS, Psychological distress (PD) and control variables like (gender, age, time lived in the country and regularity of contact with family and friends) was the multivariable logistic regression. The study revealed that there was a significant relationship between PD and SRHS for all urban areas, particularly in Western European countries (adjusted OR=3.615, 95\%, $\mathrm{Cl}$ : 3.333-3.920 $\mathrm{p}<0.001)$. Time lived in a country of residence, financial stability and regularity of contact with family and friends were negatively related with signs of PD in the adjusted model. Conclusively, the study discovered that there is a strong significant relationship between SRHS and Psychological distress.

Kimengsi, Ndi \& Akhere (2015), carried out some research work based on urban housing improvement and conflict prevention framework for Cameroonian cities: Lessons from Kumba-Cameroon. They noticed that the rapid growing population of Kumba, like other Cameroonian cities suffer from the challenges of poor and adequate housing conditions which play negatively on their health. This study employed using interviews of sixty directly affected inhabitants and three focus group discussion and some information gotten from some secondary sources. 
The results indicated that the factors causing housing conflicts in Kumba were: population increase from rural areas, inadequate shelter, difficulty in getting building permits from the City councils, poor urban planning, nonrespect of building codes, poverty and high rents. The study suggested that state development stakeholders like the Delegation of Urban Development and Housing, Landlord and City Councils of each region of Cameroon should endulge and implement policies that favour housing especially for the low-income groups that suffer poor housing conditions in the country.

In the same light, Egoh \& Kakdeu (2021), evaluated the problem of the proliferation of informal housing in major cities in Cameroon. According to them, there are a series of factors that indicate why this problem is becoming so frequent. Some of these indicators include a deficit of housing supply, unaffordability issues, critical market factors, weak legal and institutional systems, and the socio-economic conditions of the country. This article focuses on the roots of Cameroon's informal housing crisis and employs a content analysis method in collecting data. It explores some of the negative conduits to the housing problem and propose key recommendations to the government that can help improve the situation.

Fombe (2014), examines the effect of Housing Standards on Household Health and Disease Nexus in the Buea Municipality-Cameroon. This study seeks to examine the physical characteristics of houses and their standards in relation to health and disease. Data was collected through observations and interviews. Field data reveals that over $70 \%$ of the housing standards have improved over the past two decades. This notwithstanding, there is a positive correlation between standard/substandard housing on the one hand and disease/poor health conditions on the other. This is mostly linked to housing type, structural layout and environmental conditions as observed in parts of the rapidly urbanizing settlement of Buea; a university town and regional capital of the Southwest in Cameroon. In order to reduce the proliferation of communicable diseases like typhoid, cholera and malaria, housing upgrading and refurbishments should be matched with local planning objectives if improved health is to be anticipated by the population in this tropical settlement. The research of Fombe (2014) goes in line with this research work though the study area, objectives and findings differ. This is an indication that there is a need of improvement in terms of housing and health in Cameroon.

\section{RESEARCH METHODOLOGY}

\subsection{Background Information to Area of Study}

Cameroon, officially called the Republic of Cameroon is a country in central Africa. It is bordered by Central African Republic to the south by Congo, Gabon and Equatorial Guinea and to the west by Nigeria. The climate is humid tropical in south, tropical dry north, the average temperature ranges between $25^{\circ} \mathrm{C}$ and $32^{\circ} \mathrm{C}$ South to North. Vegetation in Cameroon is dominated by savannah in the north and northwest on a large volcanic chain that extends from Mount Cameroon Mountains Rhumer up through the mountains languid; higher pastures in the highlands of central and West; rainforest and swamps in the south and east. Cameroon has 10 regions and 58 departments. Cameroon 2020 population is estimated at $\mathbf{2 6 , 5 4 5 , 8 6 3}$ people at mid-year according to UN data.

The housing quality components constitute: the physical components like household size, the internal housing factors like electricity and water supply and the environmental housing indicators like crime wave, satellite, internet and many others. The Human Development Report (2020), gives some statistics on some of these housing factors in Cameroon.

Electricity supply, hitherto provided by SONEL was privatized in recent years in favor of a U.S. company under the new name AES Sonel. 58 of 58 departments are electrified, 188 chief towns of district 360 . The rate of access to electricity in rural areas is 5\%. The rate of access to electricity in cities between 45 and $50 \%$. The coverage in terms of electrification is $\mathbf{3 6 \%}$. The water supply in Cameroon was provided by the National Water Company of Cameroon (SNEC), which itself has been privatized to make way for a private trader (Cam Water). $46 \%$ of the national population has no access to safe drinking water in urban centers. The coverage is still very low, between $30 \%$ and $55 \%$ in urban and suburban areas. In rural areas, about $\mathbf{3 0} \%$ of the population is supplied with drinking water. This study concentrates of some of these housing quality components for Cameroon and looks at their effect on public health status of the Cameroonian citizens.

\subsection{Sources of data collection}

The study uses the 2014 Cameroon Household Consumption Survey (CHCS 4). CHCS 4 is the most recent data collected by the National Institute of Statistics in Cameroon. It is the fourth of its kind to be undertaken in Cameroon after those of 1996, 2001 and 2007. The fourth CHC survey targeted the ten regions of Cameroon and the political (Yaoundé) and economic capital (Douala). (Epo et al., 2011).

\subsection{Sampling population}

The targeted sample consisted of 50,000 households, of which 46,090 households were effectively visited. The national territory was divided into urban and rural, $50.10 \%$ of the sample population data was derived from the rural area while $49.90 \%$ was obtained from households who lives in the urban area. The sample population was 
divided into 1024 cluster zones which from which data was collected through the administration on the questionnaire. The questionnaire used had 17 sections of which 2 are optional. In each sampled household, 16 sections were administered of which 15 are obligatory (sections 00 to 14) and one optional (section 15 or 16). The administration of these various sections implied several passages in each household depending on the area of residence of the household (6 visits in urban areas and 3 in rural areas).

\subsection{ANALYTICAL FRAMEWORK AND MODEL SPECIFICATION 3.4.1 Model Specification for Objective One}

Objective one identifies the determinants of housing quality in Cameroon. Housing quality is a multifaceted concept and can adequately be measured by considering so many indicators. Housing quality is a broad term that encompasses many aspects and has both an objective and a subjective dimension. (Brkanić, 2017). The objective dimension embodies aspects like: dwelling type, number of rooms, presence of facilities, and the condition of the dwelling. The subjective dimension includes user characteristics that lead to specific needs, desires, and expectations. In summary, housing quality criteria include housing conditions such as the characteristics or properties of a physical environment and the characteristics of its users. (Streimikiene, 2015). The notion of housing constitutes factors like: environmental factors, physical housing indicators, the internal housing environmental component, the external housing environmental component. (Dieneret al., 2010). Housing is therefore the process of providing a large number of residential buildings with adequate physical infrastructure and social amenities in planned, decent, safe and hygienic neighbourhood to meet the basic and special needs of the population

Measuring housing conditions and their effects on people's well-being is a complex task because there are very few comparable indicators. From the ten Housing quality indicators of (Dieneret al., 2010), the set of indicators to measure housing conditions for this study would include: The Physical Housing Indicators for Assessing Quality of Life in Cameroonian characteristics of the dwelling (e.g household size), the Internal Housing Environmental Component include: availability of electricity, water supply, indoor flushing toilets, bathroom requirements, cooking facilities, the quality of materials and construction and whether parts of the dwelling are deteriorated or damaged. The External Housing environmental component constitutes: Unit and neighbourhood qualities like: Crime, violence or vandalism in the area, Pollution, Roofing exposure to noise, satellite, internet, etc. The 2014 Cameroon Household Consumption Survey (CHCS 4), constitutes a total sum of 38 housing quality components. In this study, we work only on few housing quality determinants. Here the Ordinary Least Square or the Simple Multiple Regression Analytical Framework will be employed to get the housing quality indicators.

In order to examine the determinants of housing quality in Cameroon, the model is specified as follows.

\section{HOI_n $=\mathbf{f}($ TOP, BUH, NSE, MOS, WASD, WATS, ELECS)}

HOI_n $=\lambda_{0}+\lambda_{1}$ TOP $_{i}+\lambda_{2}$ BUS $_{i}+\lambda_{3}$ NSE $_{i}+\lambda_{4}$ MOS $_{i}+\lambda_{5}$ WASD $_{i}+\lambda_{6}$ WATS $_{i}+\lambda_{7}$ ELECS $_{i+\varepsilon i}$ (1)

Equation (1) above examines the relationship between housing quality (HOI_n) and its indicators: Topography (TOP), Bush at the environment (BUSH), noise (NSE), mosquitoes (MOS), waste disposal (WASD), water channels (WATLS) and electricity source (ELECS). The housing quality score is computed using the Multiple correspondence analysis, where an index of the thirty-eight (38) physical, internal and environmental housing components in Cameroon was computed and normalized to take values between 1 and 0 . The value 1 indicates good housing quality and 0 represents a poor housing quality.

\subsubsection{Model Specification for Objective Two}

Objective two consists of Modelling the effect of housing quality on self-reported health status

In order to analysis the effects of housing quality on self-reported health status, the adopted method for this estimation is the ordered probit or logit model. This is because the modalities of the dependent variable (selfreported health status) are ordered. In CHCS 4, the question item that captured the self-reported health status is Likert scale question with the following responses options very good, good, neutral, bad, or very bad.

The model:

$\mathrm{SRHS}_{\mathrm{I}}=\lambda_{0}+\lambda_{1} \mathrm{TOP}_{\mathrm{i}}+\lambda_{2} \mathrm{BUS}_{\mathrm{i}}+\lambda_{3} \mathrm{NSE}_{\mathrm{i}}+\lambda_{4} \mathrm{MOS}_{\mathrm{i}}+\lambda_{5} \mathrm{WASD}_{\mathrm{i}}+\lambda_{6} \mathrm{WATS}_{\mathrm{i}}+\lambda_{7} \mathrm{ELECS}_{\mathrm{i}+\varepsilon \mathrm{i}}$ (2)

Where SRHS is self-reported health status which is order categorical variable; $\lambda 0$ is the constant; $\lambda$ are the parameters; the exogeneous variables for housing quality are topography (TOP), noise (NSE), mosquitoes (MOS), water disposal (WASD), water channels (WATLS), electricity source (ELECS) and ci is the error term. Here, a multiple correspondence analysis is computed using the housing quality components, in order to have the housing quality index. This is normalized to have the housing quality score (HOI_n). In the ordered logistic regression, this housing quality score is used in place of the exogeneous variables and combined with control variables like marital status $(0=$ single and $1=$ married $)$, age, place of residence $(0=$ rural and $1=$ urban $)$, educational years and the income of the primary sampling unit or clusters (income_av_psu) 


\section{PRESENTATION AND DISCUSSION OF RESULTS}

\subsection{PRESENTATION OF RESULTS BY OBJECTIVES}

4.1.1Objective one results: The determinants of housing quality in Cameroon

Table 4.1: Empirical Multiple regression results of some housing quality indicators in Cameroon

\begin{tabular}{|c|c|}
\hline & $(1)$ \\
\hline VARIABLES & HQI_n (housing quality score) \\
\hline \multirow[t]{2}{*}{ Household size } & $-0.00353 * * *$ \\
\hline & $(0.000126)$ \\
\hline \multirow[t]{2}{*}{ Topography } & $0.00549 * * *$ \\
\hline & $(0.00119)$ \\
\hline \multirow[t]{2}{*}{ Bush } & $0.0645^{* * *}$ \\
\hline & $(0.000980)$ \\
\hline \multirow{2}{*}{ Noise } & $-0.116 * * *$ \\
\hline & $(0.00116)$ \\
\hline \multirow{2}{*}{ Mosquitoes } & $-0.0175 * * *$ \\
\hline & $(0.00126)$ \\
\hline \multirow[t]{2}{*}{ Waste disposal } & $-0.0501 * * *$ \\
\hline & $(0.00163)$ \\
\hline \multirow[t]{2}{*}{ Water channels } & $-0.124 * * *$ \\
\hline & $(0.00159)$ \\
\hline \multirow[t]{2}{*}{ Electricity source } & $-0.200 * * *$ \\
\hline & $(0.00129)$ \\
\hline \multirow[t]{2}{*}{ Constant } & $0.836 * * *$ \\
\hline & $(0.00238)$ \\
\hline Observations & 46,090 \\
\hline R-squared & 0.783 \\
\hline
\end{tabular}

Source: Computed by Author based on the Cameroon Household Consumption Survey (CHCS 4, 2014)

Following the (CHCS 4, 2014) data, the household size ranges from a minimum value of 1 to a maximum value of 30 household members. The number of observations (household) were 46,096. Table 4.1 above indicates that a larger household size (30 household members), will lead to a $1 \%$ significant fall in housing quality by $0.3 \%$. This indicates that housing quality will be improved if the members of household are few. Secondly, a good topography and an available bush or vegetation around the household premises, will have a $1 \%$ significant improvement on housing quality by $0.1 \%$ and $6 \%$ respectively.

Thirdly, if a household environment has many mosquitoes, poor waste disposal provision, little or no water channels and poor electricity availability, the housing quality have a $1 \%$ drop by $1 \%, 5 \%, 12 \%$ and $20 \%$ respectively. It is therefore evident that the physical, internal and the environmental housing components are so essential in determining the housing quality for all Cameroonians. An improvement in all these indicators will improve on the housing living conditions for the citizens.

The R-squared value is the coefficient of determination. Table 4.1 above indicates that the R-squared is $78 \%$. This means that the housing quality components indicated in the model account for $78 \%$ of the housing quality indicator. The rest of the $22 \%$ components that are not mentioned in the model also influence the housing quality. Therefore, Cameroonians should be provided with proper water supply facilities, waste disposal units, proper electricity to guarantee a comfortable housing environment as their dwelling.

To test the overall significance, we use the F-Statistic value and the probability value found in Appendix I below. Following the detailed results of objective one in Appendix 1 below, the overall probability value (Prob $>$ $\mathrm{F}=0.0000)$. The F-statistic or F-calculated value (F8, 46,081) degrees of freedom is 8046,10 and it is greater than the results from the F-table which is 2045.22. This is a clear indication that on a whole, the housing quality components significantly determinant the housing quality of the Cameroonian citizens.

4.1.2 Objective Two results: The effect of housing quality on self-reported health status of Cameroonians 4.1.2.1 Descriptive statistics for self-reported health status (SRHS)

The second objective assesses the effect of Housing quality on self-reported health status (SRHS) of Cameroonians. Ordered logistic regression is applied as an analytical tool because SRHS is an ordered categorical status. From the questionnaire of Cameroon Household Consumption Survey (CHCS 4, 2014), the respondents were asked to 
declare the state of their health. The options given were to indicate if the health was very good, good, average, bad or very bad. The various responses are indicated in Table 4.2 below. Following the results in Table 4.12 below, $43.1 \%$ said their health was very good, $46 \%$ of them acknowledged that their health was good, $9.9 \%$ had average health, $0.7 \%$ had bad health and $0.13 \%$ had very bad health. The respondents were allowed to select any of the options according to their state of health as per that period. This justifies ordered logistic regression as an appropriate methodology of analogy. The results of this regression are summarized in Table 4.2 below.

Table 4.2: Descriptive statistics of the Self-Reported Health Status (SRHS)

\begin{tabular}{|c|c|c|c|}
\hline $\begin{array}{l}\text { Appreciation } \\
\text { of the state } \\
\text { of health }\end{array}$ & Freq. & Percent & Cum. \\
\hline \multicolumn{4}{|c|}{ 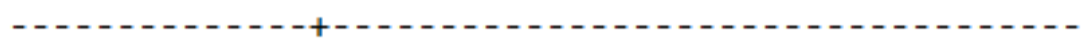 } \\
\hline very good & 19,747 & 43.16 & 43.16 \\
\hline good & 21,076 & 46.06 & 89.22 \\
\hline Average & 4,551 & 9.95 & 99.17 \\
\hline bad & 321 & 0.70 & 99.87 \\
\hline very bad & 59 & 0.13 & 100.00 \\
\hline \multicolumn{4}{|c|}{ - - - - } \\
\hline Total & 45,754 & 100.00 & \\
\hline
\end{tabular}

Source: Computed by Author based on the Cameroon Household Consumption Survey (CHCS 4, 2014

4.1.2.2 Empirical results of the Ordered Logistic Regression Results on Housing quality and Self-Reported Table 4.3: Ordered Logistic Regression Results on Housing quality and self-reported health status

\begin{tabular}{|l|c|}
\hline & $(1)$ \\
\hline VARIABLES & self_health \\
\hline $\begin{array}{l}\text { Housing quality index normalized score (HQI_n) } \\
1=\text { good housing quality } \\
0=\text { poor housing quality }\end{array}$ & $0.273^{* * *}$ \\
\hline Educational years (educ_years_sq) & $0.0995)$ \\
\hline Gender $(0=$ male, $1=$ female) & $0.000507^{* *}$ \\
\hline & $0.000212)$ \\
\hline Zone of residence $(0=$ rural, $1=$ urban) & $0.0455^{*}$ \\
\hline & $(0.0245)$ \\
\hline Age & -0.00732 \\
\hline & $(0.0306)$ \\
\hline $\begin{array}{l}\text { Income_av_psu [income of the primary sampling unit or cluster } \\
\text { (psu)] }\end{array}$ & $-7.16 \mathrm{e}-06$ \\
\hline Marital status $(1=$ married and $0=$ single) & $(1.18 \mathrm{e}-05)$ \\
\hline & $-7.44 \mathrm{e}-08^{*}$ \\
\hline Household size (hs_sq) & $(3.97 \mathrm{e}-08)$ \\
\hline & -0.0454 \\
\hline Constant cut1 & $(0.0288)$ \\
\hline & $9.25 \mathrm{e}-05^{* *}$ \\
\hline Constant cut2 & $(0.000178)$ \\
\hline & -0.0776 \\
\hline Observations & $(0.0791)$ \\
\hline
\end{tabular}

$$
\begin{aligned}
& \text { Standard errors in parentheses } \\
& * * * \mathrm{p}<0.01, * * \mathrm{p}<0.05, * \mathbf{p}<0.1
\end{aligned}
$$

Source: Computed by Author based on the Cameroon Household Consumption Survey (CHCS 4, 2014)

The results in Table 4.3 above indicate three cut off points (Constant cut1 and Constant cut2), representing the intercepts of constant. These intercepts stand for the various categories of self-reported health status (SRHS) of the household heads. In this context, the two cut-off points indicate that there are three categories of the 
responses indicating the state of health of the respondents which are namely: very good, average and bad health state. The following paragraphs indicate the effect of each of the independent variables on SRHS.

Firstly, housing quality (HOI_n), representing (the external, internal and physical housing components), would determine the health status of a household heads. The housing index ranging between 0 and 1 . A good housing quality takes the value of 1 while a poor one takes 0 . Results in table 4.3 above show that a good housing quality will likely have a $1 \%$ significant improvement in the health of the respondents by $27 \%$, as they move from a lower health category to a better health status. This implies that a poor housing quality will likely cause lowincome earners in Cameroon to instead fall sick, thus hampering their health status.

The income (Income_av_psu) of household members in the1024 clusters or primary sampling units as indicated in the Cameroon Household Consumption Survey (CHCS 4, 2014) data, will greatly influence the nature of housing of the citizens. Results on table 4.3 above indicate that there is a likelihood that the low-income earners of the primary sampling units, will have a 5\% significant fall in their housing quality by 7.1 units, unlike those of the high-income earning groups. It is so glaring that income inequality leads to housing inequality and consequently a fall in the health status of the low-income earners.

The educational years ((educ_years_sq)) of household heads greatly influences their housing quality and thus their health status. In this light, a household head that is highly educated-with so many years of education, will have a likelihood of having high quality houses and thus maintaining a higher category of health status by $0.05 \%$. This is significant at $5 \%$ level of significance. This indicates that those who have attained higher educational status will likely have a good health status than those at a lower educational level or few years of education.

Household heads of higher age groups, are more likely to be in a lower category of health by 7.16 units. That is, as household heads grow on in years, there is a likelihood that their housing quality may drop in terms of housing facilities and thus they will drop from a higher health category to a lower one. In other words, their housing quality deteriorates as well as their health status as they grow on in age.

The household size ((hs_sq)) also has an impact on housing quality and thus on SRHS of the household heads in Cameroon. A unit increase in the number of people living in a household, for example, thirty household members, (indicating overcrowding), will cause the likelihood of a 5\% significant fall in housing quality and consequently a shift from a higher category of health to a lower category of health status by 9.25 units. Therefore, the higher the crowd of people in a household, there will be a 5\% significant fall in the housing conditions and thus a drop in the health situation of its members.

The zone of residence (urban or rural) has an insignificant influence on housing quality and SRHS of the respondents. Household heads that move from an urban area of settlement to a rural area, will likely have an insignificant fall in their housing quality and health status than their counterparts who are resident in rural areas by $2 \%$ units.

Gender ( $1=$ female and $0=$ male household heads) too plays a very vital role on housing quality and health status of Cameroonian household heads. Male Household heads, will likely enjoy a 5\% significant rise in housing quality and good health than those that are female by $4 \%$. From all indications, female household heads fall at a lower category of health than their male colleagues, due to poor housing conditions.

Marital status $(0=$ single and $1=$ married $)$ has an insignificant effect on housing quality and SRHS. A household head that is single will have a likelihood of a fall in his/her housing condition and thus health status by $4 \%$. Therefore, housing quality and its influence on the health status of Cameroonians does not depend on marital status. It is obvious that good housing conditions and health are independent of the individual marital situation. In Cameroon we have a good proportion of people in a single marital status having good houses and health as well as those that are married. It depends on their income situation- whether they are low income or high-income earners.

\section{RECOMMENDATIONS AND CONCLUSION \\ 5.1 Recommendations/ Policy Implication}

This section constitutes the presentation on the various policy recommendations based on the findings of this thesis. We present these policies based on how the two central variables (housing self-reported health status) of Cameroonians

- The results obtained in this study indicate that housing quality has a significant effect on the self-reported health status of Cameroonians. A good house status will enhance the health of household and a poor house quality will have negative health effect on the household members. It quite evident that the Cameroon government is conversant with this reality. Regarding the housing quality policy, Section 9, question 8 of the Cameroon Household Consumption Survey CHCS 4, 2014) data, indicates that the government had engaged in the construction of houses for its citizens. This could reduce the social inequality in connection to housing quality. Therefore, the construction of houses will help decongest the houses that are of bigger household sizes. This in turn will reduce the risk of diseases due to overcrowding in homes. It's all a chain of effects. Good housing quality enhances health and a healthy household head is a guarantee of acquiring more income. The houses should also 
be made affordable even to low-income earners

- In order to solve the problem of housing inequality, the government of Cameroon should make an effort to implement a localized planning and promote advanced information management system. This can be realized by identifying suitable housing standards for the cities in the near future

- In addition, following the present initiative by the government of start the decentralization process, the local governments should provide a variety of housing alternatives with regards to tenancy and payment, such as short-term rental, long-term lease, cohousing, and financed purchase. This will help remedy the problem of availability and affordability thus curbing the problem of housing inequality in Cameroon.

- Concerning the self-reported health status, Section 9, question 8 of the Cameroon Household Consumption Survey (ECAM 4, 2014), proposes a good policy to guarantee a constant quality of life in the ambit of the health of the various household heads. Most respondents indicate the necessity for the government to ensure a free access to medical facilities. If the majority of the population have sponsored health expenses from the government, this will curb even the health inequalities among the poor and non-poor. There is a result chain of the policy interventions. A household head with a good quality adjusted life year, will be guarantee a higher productivity the job site, a higher income and consequently a good housing quality

- Differences in early educational levels or years as indicated in this study is another important component contributing to persistent inequality housing conditions and health across among the poor and non-poor classes. The results of this study show that the educational level influences housing quality and health status positively. The majority of those with higher educational years, earn higher and thus obtain good housing quality and subsequently good health status. It is so evident that Education policies matter. Policies that promote equal access to educational facilities may help reduce income inequality, housing inequality as well as health inequality.

\subsection{Conclusion}

Housing is one of the most challenging areas that cause suffering and social inequalities to most households in Cameroon. Some of the factors that cause this housing discomfort and conflicts are: population increase in most cities, inadequate shelter, Institutional changes (including housing building permits), poor urban planning and nonrespect of building codes), poverty and high rents. The results from this study pulls us to assert that income inequality or relative income can be considered as one of the mechanisms through which social inequalities may translate into poor housing conditions for the non-poor and consequently drift them in to health inequalities. In other words, less affluent residents and households are more exposed to and affected by inadequate housing conditions and associated health risk factors. Therefore, inadequate housing conditions have a significant negative impact on health outcomes such as malaria, typhoid, respiratory diseases, etc. as shown in the Cameroon Household Consumption Survey (CHCS, 2014) data set.

Precisely, results reveal that the effect of inadequate housing conditions is visible in all income or socioeconomic groups, although their expression tends to be clearer within disadvantaged households and residents. Still, the most relevant example from public health perspective may be that the real health challenge lies within the identification of and provision of support to those households and residents suffering from multiple exposures. Since the gap between the rich and poor is still growing, the reduction of inequalities is becoming a topic of increasing relevance, especially in countries like Cameroon, with insufficient social and health security mechanisms. The results clearly indicate that income inequality, bad housing conditions and poor health often are interwoven. There is a strong need for policymakers and local stakeholders to intervene and develop programmes to overcome such inequalities and provide adequate housing conditions for everyone. We recommend that daily living conditions to be improved as a first step towards tackling social disparities.

It is therefore obvious that the housing conditions for most Cameroonians need to be improved. This entails that improving the quality of housing refers to raising the quality of housing that is affordable for low-, moderateincome people and encouraging environmentally responsible building and development. In addition, the housing should be livable, well-designed, having a suitable location, and containing all internal favourable housing components.

\section{LIST OF REFERENCES}

Adekunle F., Ogundare J., Olayinka-Alli L., Mayowa A., Temilade B., Opeyemi E., Olamide O., \& Ibiwunmi S. (2018). Housing Quality and Risk Factors Associated with Respiratory Health Conditions in Nigeria. Published November 2018 DOI: 10.5772/ intechopen.78543

Baker, E., Lester, L. H., Bentley, R. \& Beer, A. (2016). Poor housing quality: Prevalence and health effects. Journal of Prevention \& Intervention in the Community. Volume 44, 2016 - Issue 4: Residential Context and Health in Australia

Bonnefoy, X. (2007). 'Inadequate housing and health: an overview', Int. J. Environment and Pollution, Vol. 30, Nos. 3/4, pp.411-429.

Boscardin, C.K., Gonzales, R., Bradley, K.L., \& Raven, M.C. (2015). Predicting cost of care using self-reported 
health status data. BMC Health Serv Res 2015; 15:406

Diamond Reality Real Estate Company Cameroon (2019). Examining the Growing Housing Problem in Douala; the Economic Hub of Cameroon

Egoh, M. A., Kakdeu, L. M. (2021). The Proliferation of Informal Housing in Major Cities in Cameroon: Evidence, Drivers and The Way Forward. Published by Nkafu Policy Institute.

Fombe, L.F \& Balgah, S.N. (2010). Urbanization Process in Cameroon: Patterns, Implications and Prospects, Nova Science Publishers Inc. New York.

Fombe, Lawrence \& Balgah Sounders (2010). The Urbanization Process in Cameroon: Patterns, Implications and Prospects. New York: Nova.

Fombe, Lawrence (2012). Housing Dynamics and Informal Businesses in Built-Up Areas of Major Cities in Cameroon. Journal of Human Ecology 40(2), 167-175.

Fombe Lawrence (2014). Housing Standards, Household Health and Disease Nexus in the Buea Municipality. Journal of Sustainable Development.7(4) DOI:10.5539/jsd. v7n4p262

Greg, W. Nardo, F. \& Verma, A. (2017). The relationship between self-reported health status and signs of psychological distress within European urban contexts. European Journal of Public Health, Volume 27, Issue suppl_2, May 2017, Pages 68-73, https://doi.org/10.1093/eurpub/ckx008

Kimengsi, J.N., Ngala, N. H., \& Akhere, S. G. (2015). Urban housing improvement and conflict prevention framework for Cameroonian cities: Lessons from Kumba. Journal of Geography and Regional Planning. Article Number - E2BB05554230 Vol.8(7), pp. 181 - 188, July 2015.https://doi.org/10.5897/JGRP2015.0504

Kimengsi, Jude, Ndi, Humphrey \& Akhere, Solange (2015). Urban housing improvement and conflict prevention framework for Cameroonian cities: Lessons from Kumba. Journal of Geography and Regional Planning8(7), 181-188.

The Parliamentary Office of Science and Technology (2011). Housing and Health. Postnote post@parliament.uk www.parliament.uk/post

Krieger, J., \& Higgins, D., Housing and health: Time again for public health action, American Journal of Public Health, pp. 758-768 (2002)

Maêns, R. \& Bengt Ha glund (2001). The Importance of Health and Medical Care for Public Health. Centrefor Epidemiology, National Board of Health and Welfare, S E -106 30 Stockholm, Sweden.

Quddusi, M. Alam. (2020). Importance of Good Health in Our Life - How can we achieve Good Health and Well Being? The Scientific World.

Routledge. U.S. Department of Housing and Urban Development, American Housing Survey (2007). Retrieved from U.S. Department of Housing and Urban Development: http://www.huduser.org/DATASETS/ahs/ahsdata07.html Archived 2012-04-04 at the Wayback Machine

Subramanian, S.V., Huijts, T. \& Avendano, M. (2010). "Self-reported health assessments in the 2002 World Health Survey: how do they correlate with education?". Bulletin of the World Health Organization. 88 (2): 131-8. doi:10.2471/BLT.09.067058. PMC 2814481. PMID 20428370

The World Bank (2002). Upgrading Low Income Urban Settlements-country Assessment Report, Cameroon

UN-HABITAT (2009). Harmonious Cities: State of the World's Cities 2008/2009, London www.clc.org.sg/pdf/UN- HABITAT20Report\%20Overview.pdf. Accessed on 30/09/2009.

United Nations. "World Population Prospects 2020".

WHO (2018). WHO Housing and health guidelines Geneva: World Health Organization; 2018. License: CC BYNC-SA 3.0 IGO 
APPENDIX I: DETAILED MULTIPLE REGRESSION RESULTS OF SOME DETERMINANTS OF HOUSING QUALITY IN CAMEROON

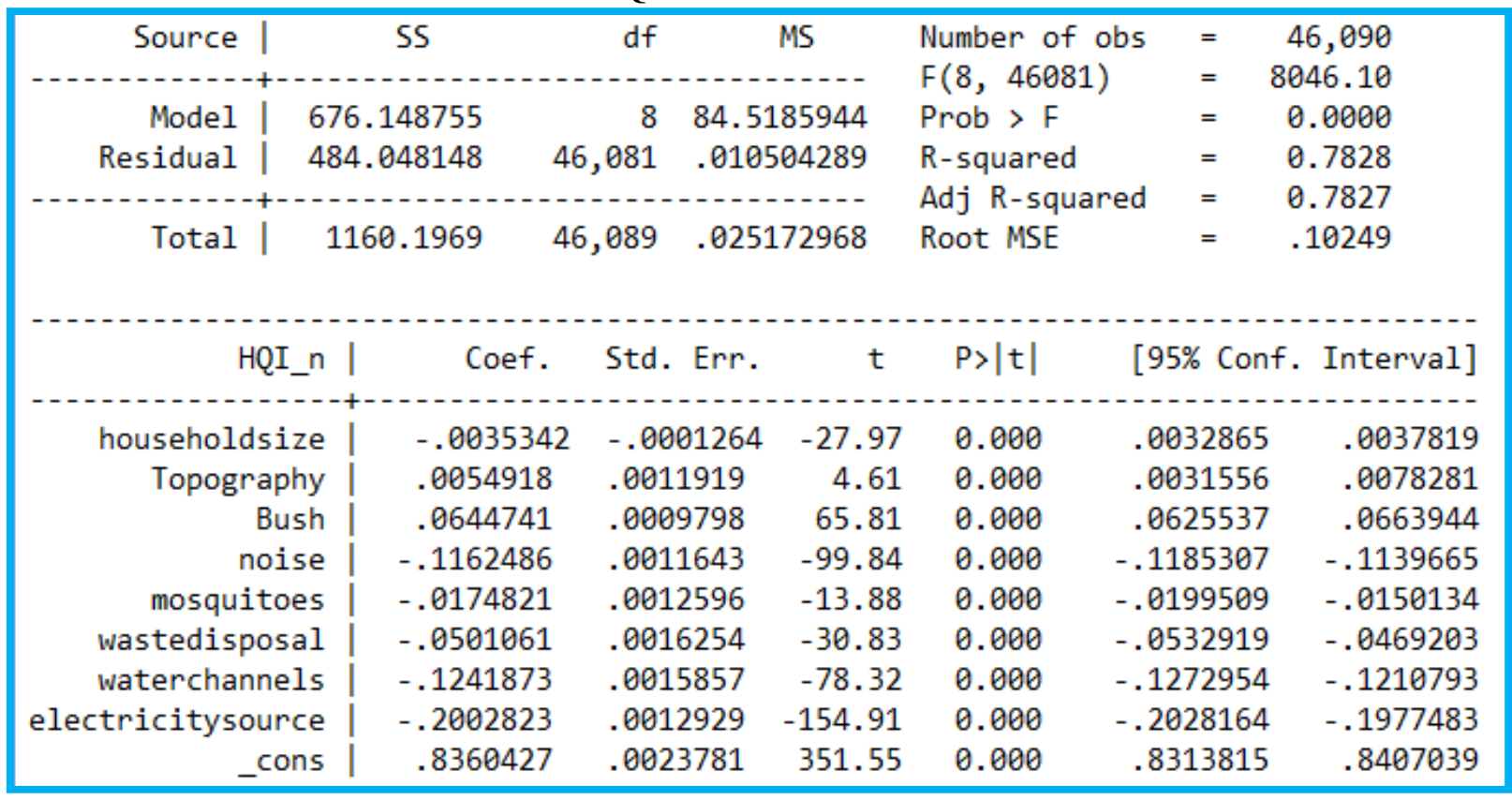

APPENDIX II: OBJECT TWO RESULTS- THE EFFECT OF HOUSING QUALITY ON SELFREPORTED HEALTH

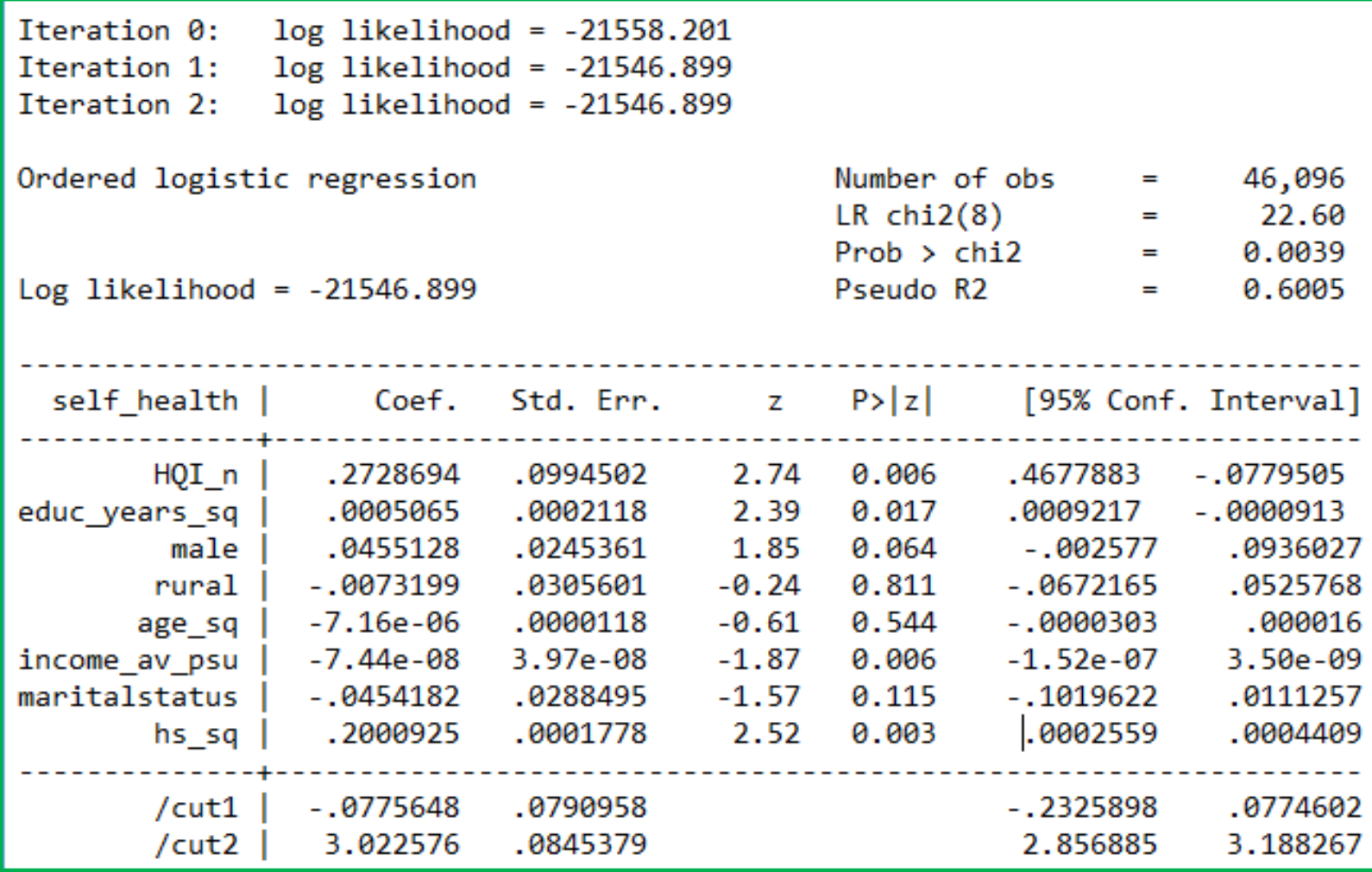

